such questions as: Can advance directives be ethically acceptable? Can treatment be ethically refused? Should advance declarations be legally binding? The booklet provides a sample Christian advance declaration for the management of serious illness.

One of the conclusions of the booklet is that many of the current advance directives are seriously objectionable on moral grounds. It is stated in support of this that: (i) the autonomous demands of patients may clash with the conscientious objections of doctors; (ii) respect for mentally incapable persons is not shown by blindly seeking to respect their past wishes but by acting in their best interests; (iii) it is morally unacceptable to refuse treatment on the basis that one's life in some anticipated condition is unacceptable and for that reason would be better ended.

The authors explicitly state that it is never morally right to withdraw assisted nutrition and hydration with the intention, purpose or aim of ending life. They go onto classify living wills into two types: the first being a specific refusal of treatment because, for example, it is too burdensome or too costly, for example, the refusal of blood products by a Jehovah's Witness and the second being the refusal of a wide range of treatments when one reaches a certain state of illness. It is suggested that the former advance refusal is ethically proper, but the latter not. It is stated that the latter is in fact to ask for death by withdrawal of treatment and is morally suicide.

The booklet is, however, slightly misleading in some respects. The authors state that the question of whether a living will is legally binding has not yet been formally tested in court. In fact a Canadian court has ruled that an applicable advance refusal of treatment is legally binding on a treating doctor and various judicial statements in courts in England and Wales have indicated that courts in this jurisdiction are likely to take the same approach.

The authors state that they agree with the view of the British Medical Association (BMA) that advance statements, although not binding on health professionals, deserve thorough consideration and respect. The BMA is, however, clear in its publication Advance Statements about Medical Treatment that where valid and applicable, advance refusals must be followed.

Whilst some people may not agree with the views and opinions expressed in the Guild of Catholic Doctors' booklet, it is an important and significant contribution to the diversity of views that have been offered on the ethical issues surrounding the use of living wills. I would recommend it to anyone concerned with the ongoing debate.

STEVEN LUTTRELL

Centre for Geriatric Medicine,

University College London Medical School

\section{Medical Harm: Historical, Conceptual and Ethical Dimensions of \\ Iatrogenic Illness}

Virginia F Sharpe and Alan I Faden, Cambridge and New York, Methuen, 1998,280 pages, $£ 50.00$ hc, $£ 17.95$ sc.

Of the many seekers after a healthier life or of relief from suffering who rightfully expect benefit from the health care system some are more harmed than helped. This is a serious matter which the authors of this timely, readable, and informative book address seriously. ... They deal mostly with harmful medical events which happen in the course of modern management of conditions treated in acute hospitals: but the book admirably lives up to its full title.

Following a thorough, wide ranging and insightful examination of the historical and bioethical context the authors come up with the term "comiogenic harm" to best express the notion of iatrogenic illness as it occurs nowadays. They reject the pessimistic view that harm is an inevitable and inescapable concomitant of medical progress, and maintain that the corporate hubris which fosters professional hegemony, and the imperfections of cost-driven care systems are fundamental to the mala praxis that engenders avoidable illness, injury and dissatisfaction.

The book reflects the increasing public, political and economic concerns and expectations about health matters. Although the authors refer to the United States in particular their message reaches the many "Western" countries which face similar issues and tend to follow socio-economic and cultural trends set in the USA. The emergent case for an up-to-date and appropriate patient-centred fiducial contract instead of well-meaning. doctor-centred texts is clearly made.

The essential feature of such a con? tract should be a binding obligation oi the health care provider to fulfil specified duty of care to the consume (patient). This demands from the pro vider personal integrity and profesy sional competence, and it gives the patient full partnership in the formula tion of the treatment plan or of the research protocol.

Topics which, unsurprisingly view of their high profile, receiv extensive coverage include: adversieu drug effects; hospital infection; unnecessary surgery, and the prematurgs introduction of unproved interven? tions. From this and other welf researched and fully documented $\mathrm{ma}=$ terial the authors conclude that muc iatrogenic illness could be avoided doctors were always equipped to apple appropriate knowledge and technic skills to meet the specific needs of the individual patient. Shortcomings is these respects are seen to derive from baneful attitudes inculcated by value largely established by self-regulatin and self-seeking professional bodie that unduly influence medical eduç tion and clinical training, set an $\phi$ maintain standards, and discipline miscreants. Other ways by which the interests of patients suffer include. incomplete and sometimes misleading information; restricted communication; limited participation in decision making and frustration that doctores appear to be impervious to criticist and reluctant to apply rigorous quali control to their output.

The authors put forward a package of measures designed to limit harm bø the promotion of good practice rather than by more stringent disciplina measures. Their demand for a moreopen and accountable medical profes sion is now widely accepted as is the need for re-negotiation of the doctore patient contract. Medical education No undergoing one of its periodic revolugo tions with a new look that will make among other things, teaching of medical ethics mandatory and, it is to b® hoped, encourage both critical thinking and a more humanistic approach Clinical training and continuou medical education are now high on the agendas of professional bodies tha claim the right to ensure that the patient is safe in the hands of their members. There are helpful sections on highly relevant topics such as audit evidence based medicine, risk-benef (harm-good) analysis and the benef? cial uses of information technology. 
The place of these important tools for medical practice, education and research and as aids to the enlightenment of patients is well explained and fully expressed

The authors have carried out an excellent, timely and scholarly review of iatrogenic illness. It is my hope that they will examine in a subsequent book such topics as commerciogenic medical harm (marketing of medicines and infant formula) mediogenic medical harm (premature proclamation of "breakthroughs" and unbalanced scare stories) political medical harm (subordination of health care to weaponry, and medical involvement with torture), and ideological medical harm (denial of medical care to women, sanctity of life, abortion, euthanasia, terminal care).

THOMAS E OPPE Emeritus Professor of Paediatrics

\section{Ethical Issues in Mental Illness}

\section{Caroline Dunn, Aldershot, Ashgate \\ Publishing, 1998, 201 pages, $£ 39.95$.}

Caroline Dunn's book places autonomy at the centre of ethical debates about mental illness and its treatment. Her account differs from some others insofar as she is keen to make sure that the "voice" of mentally ill patients and their families is heard throughout her book; and she suggests subtly (and sometimes not so subtly) that mental health care professionals frequently fail both patients and families.

Dunn takes the view that mental illness is a valid concept, that mental illness is an illness, and therefore does not engage with questions of the validity of the concept. Rather, she goes on to explore how autonomy may be affected by mental illness. She perceives the autonomy of the mentally ill to be restricted insofar as the mentally ill lack rationality, and she spends some time discussing what rationality, or more obviously what irrationality, might mean. For Dunn, "the ability to reason" is a crucial aspect of autonomy. It is this lack of the ability to reason which makes the mentally ill patient less autonomous.

Dunn then goes on to discuss the treatment of the mentally ill and is highly critical of traditional psychiatric care. She uses excerpts from the writing of Antonia White and Jimmy Lang (who was institutionalised from a very early age for many years in different types of institutions including penal ones), and, finally, documents written by the mother of a person with schizophrenia who later died of a drug overdose. She suggests that patients are treated badly by traditional mental health care systems because they are voiceless; and that the voicelessness is one aspect of the denial of autonomy by virtue of patients' perceived irrationality. However, she is also critical of the opposite view, in which the real disabilities of the mentally ill are not properly recognised and respect for patients' autonomy is privileged above other interests; what she calls "benign neglect".

I have no doubt that Dunn is right to address the ethical dilemmas inherent in the assessment and treatment of patients with mental illnesses in terms of autonomy and restrictions on autonomy. However, I was sorry not to see in Dunn's account of autonomy any mention of the importance of emotions as being an important aspect of full rationality. Although traditional accounts of reason, and the ability to reason have always excluded experience of feeling and its expression, more sophisticated contemporary accounts of rationality concede that persons who have either too little or too much emotion are also not fully rational. This argument was hinted at by Carol Gilligan,' and developed more fully by Justin Oakley. ${ }^{2}$ Stimulating accounts have come from neuroscientists such as Anthony Damasio who have described cases of people with decreased capacity for emotion as a result of their brain damage, who also appear to have significant deficits in their capacity to reason. This of course is highly significant given that mood disorders (especially depression) are probably the commonest mental illness suffered by the general population of the mentally ill, including those with psychotic illness.

Dunn's account of autonomy does not go on to explore how different types of mental illness might impair autonomy and the ability to reason. She seems to rely heavily on accounts of patients with psychotic illnesses. However, these are only a very small proportion of patients with mental illness: similarly, she addresses (briefly) the question of compulsory detention for the protection of others, not mentioning that detained patients are very much the minority of those who are treated by mental health care professionals. The question of how and when it is justifiable to detain people on the grounds of mental illness for the protection of others is an enormously important question of course; but it is perhaps not the only issue in relation to mental illness.

Dunn raises an important concern when she questions the nature of the relationship between mental health care professionals and the relatives of patients with severe and chronic mental illness. In particular she raises the question of what duties mental health care professionals might have to such relatives. I was surprised not to see any mention of resources in her discussions; Dunn seems to suggest that most of the limitations of the mental health care system are a function of the attitudes of the professionals involved. Although this is true to some extent, it must be relevant to the provision of care that the number of inpatient beds available to mental health services has fallen by a half in urban areas like Central London. It is also well known that there is a lack of consultant psychiatrists and experienced nurses, so that many mental health services not only do not have the resources, but do not have the staff to offer a proper service either. It seems to me the other aspect of voicelessness, which Dunn rightly emphasises, is that the mentally ill are not vote winners and their needs are easily ignored.

This might seem like special pleading by a reviewer who is a psychiatrist and a psychotherapist. But I think it is misleading to present deficiencies in mental health care simply as a question of professional attitudes. There is undoubtedly much more to do in the education and training of all mental health care professionals; in particular I would argue that education in philosophy and ethical reasoning is crucial because there are so very many ethical and conceptual dilemmas in daily clinical practice. I had a sense that Dunn's heart was in the right place, but found her account of these most important issues somewhat cursory. I think there is probably room for a book which addresses itself solely to the question of the nature of autonomy and how mental illness impinges upon it, but this is not it. I found this a rather tantalising book with a broad base using broad arguments. It had for me a somewhat empty quality insofar as there was nothing in the book about the encounter between two people, which is the bedrock of the professional-patient relationship in mental health care. If Dunn is seriously concerned about the attitudes of mental health care profes- 